\section{Influence of Metal/Adsorbate Interactions on the Adsorption of Linear Alkylbenzenesulphonates to Hydrous Surfaces}

\author{
H. Motschi and J. McEvoy \\ Swiss Federal Institute for Water Resources and Water Pollution \\ Control (EAWAG), Federal Institute of Technology, $\mathrm{CH}-8600$ Dübendorf
}

Linear alkylbenzenesulphonates (LAS) account for approximately $30 \%$ of synthetically produced surfactants. The heavy usage of LAS in both households and industry is reflected in their high concentrations in stabilized sewage sludges where they can make up to $1 \%$ of the dry matter [1]. The LAS distributions observed are complex mixtures which are composed of components having alkyl chains of $C_{10}$ to $C_{15}$. It appears that the biodegradation of LAS may be severely inhibited upon sorption to particulate matter.

Amphiphilic properties of LAS are involved in a number of adsorption processes both to mineral and organic hydrous surfaces. In order to obtain some insight into such interactions on a molecular level, we have studied the adsorption of 4-(4-butylpentyl)benzenesulphonate $\left(\mathrm{C}_{10} \mathrm{BS}\right)$ on various surfaces in the presence and absence of metal ions.

Quantitation of $\mathrm{C}_{10} \mathrm{BS}$ was accomplished by high-performance liquid chromatography (HPLC), whilst molecular spectroscopies, such as electron paramagnetic resonance (EPR), were used to elucidate the nature of the bonding of the surface complex. Full details of the experimental procedures are reported elsewhere. In this paper emphasis is put on different adsorption mechanisms on distinct classes of hydrous surfaces (mineral oxides and organic matter) and potentially synergistic/inhibitive adsorbate interactions in the presence of (ad)sorbable heavymetal ions which are present in large quantities in soils and sewage sludges. Different surfaces exhibit a characteristic $\mathrm{pH}$-dependent adsorption isotherm for $\mathrm{C}_{10} \mathrm{BS}$ (Fig. 1): Hydrous oxides $\left(\delta \mathrm{Al}_{2} \mathrm{O}_{3}, \quad \mathrm{TiO}_{2}\right.$-Anatase) have a stronger tendency to adsorb LAS towards lower $\mathrm{pH}$ values, where the amphoteric surface hydroxyl group is dominantly protonated $\left(\equiv \mathrm{MOH}_{2}^{+}\right)$. Cellulose derivatives and charcoal do not show a pH-dependent sorption, this is characteristic for adsorption into channels or micropores [2]. A behaviour which shows a combination of both characteristics was found for the adsorption on dead cells of Klebsiella pneumoniae, where adsorption decreases with increasing $\mathrm{pH}$, but is not completely prevented within the $\mathrm{pH}$ range investigated (up to $\mathrm{pH} 10$ ). It has been suggested that the octanol/water partition coefficient $\left(K_{O W}\right)$ is related to the distribution ratio of hydrophobic ionizable organic compounds between the aqueous phase and the suspended organic material [3]. In view of the complex solid/liquid equilibrium conditions which follow from a multitude of association equilibria of LAS with dissolved metal ions [4], not much can be learnt from a collective approach ( $K_{\text {ow }}$ values fall in a range of 4 to $10^{2}$ ). A pronounced influence of metal-surface complexation (e.g. $(\equiv \mathrm{AlO})_{2} \mathrm{Cu}$ ) on LAS adsorption can be seen in Fig. 2 as compared with metal-free oxide suspensions. Such a shift coincides with the shift in electrophoretic mobility as a function of $\mathrm{pH}$ and/or variable metal adsorption [5] from which an electrostatic effect of LAS binding may be inferred. EPR measurements of $\mathrm{C}_{10}$ BS adsorbed on $\mathrm{Cu}^{2+} / \delta \mathrm{Al}_{2} \mathrm{O}_{3}$ confirm this interpretation, which suggests an "outer sphere" interaction of the sulphonate functional group (opposed to the claim of an inner-sphere association complex in a chloroform extract [6]). Metal ions adsorbed on hydrous cellulose derivatives show a remarkable

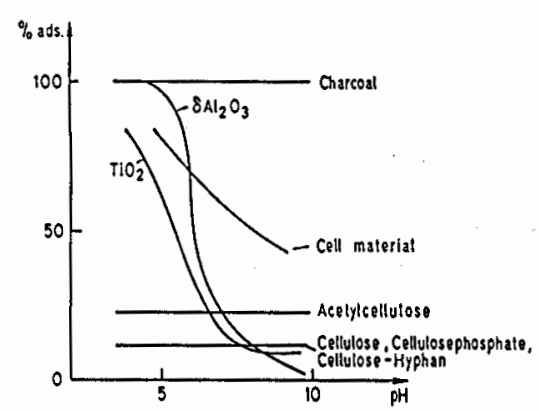

Fig. 1. Adsorption of $\mathrm{C}_{10} \mathrm{BS}$ on hydrous surfaces as a function of $\mathrm{pH}$. Concentrations: suspended solid $8 \mathrm{gl}^{-1}, \mathrm{C}_{10} \mathrm{BS}$ $2 \cdot 10^{-4} M$; except for $\mathrm{TiO}_{2} 40 \mathrm{~g} \mathrm{I}^{-1}$ and $10^{-3} M$, respectively
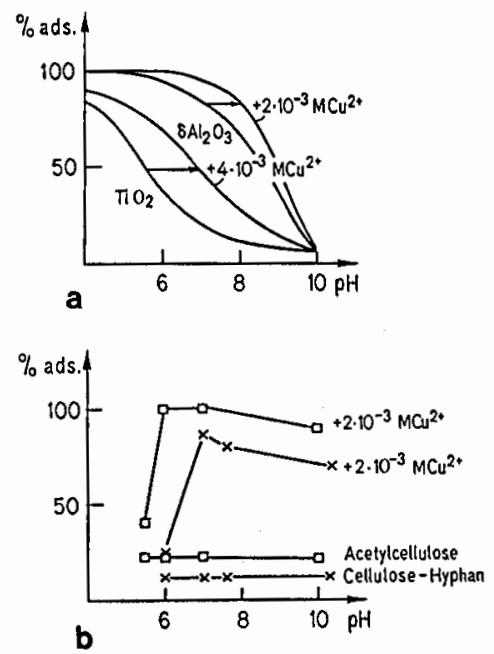

Fig. 2. Influence of $\mathrm{Cu}^{2+}$ on $\mathrm{C}_{10} \mathrm{BS}$ adsorption on a) oxide surfaces and b) organic surfaces 


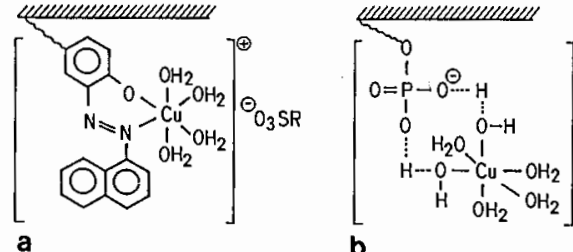

Fig. 3. Suggested surface structure of a) the ternary outer-sphere complex of $\mathrm{C}_{10} \mathrm{BS}$ with $\mathrm{Cu}_{2}{ }^{+}$- Cellulose-Hyphan (EPR parameters: $g_{\|}=2.224, A_{\|}=189 \cdot 10^{-4} \mathrm{~cm}^{-1}, \log K$ (estimated) $=18$ [11] and $b$ ) for ion association of $\mathrm{Cu}^{2+}$ aq with cellulose phosphate (EPR parameters: $g_{\|}=2.41, A_{\|}=129 \cdot 10^{-4}$ $\mathrm{cm}^{-1}, \log K$ (estimated) $\approx 2.5$ [11])

diversity of secondary effects of LAS adsorption. $\mathrm{Cu}^{2+}$ which coordinates strongly to the azo function of "Cellulose-Hyphan" drastically increases the uptake of $\mathrm{C}_{10} \mathrm{BS}$ by an outer-sphere ternary complex whereas "Cellulosephosphate" which binds $\mathrm{Cu}^{2+}$ probably through ion association has no capacity for an increased uptake of $\mathrm{C}_{10} \mathrm{BS}$ (Fig. 3). Acetylcellulose has no ionizable functional groups and forms only moderately stable surface complexes with $\mathrm{Cu}^{2+}$; yet $\mathrm{Cu}^{2+}\left(\mathrm{C}_{10} \mathrm{BS}\right)_{2}$ is adsorbed on its surface (or at interstitial locations) probably as a surface precipitate, through micellization. In an early fundamental study the role of complex formation with metal ions was assigned to play a key function in flocculation processes between electrostatically repellent sols [7]. Recently this view has been confirmed by EPR spectroscopy in the ternary system $\mathrm{TiO}_{2} /$ negative polyelectrolyte $/ \mathrm{Mn}_{\mathrm{aq}}^{2+}$ in which an increasing concentration of $\mathrm{Mn}^{2+}$ enhances the adsorption of the polycarboxylate by an outer-sphere ternary complex [8]. A priori it is not possible from the analysis of a chemical equilibrium to distinguish between surface precipitation and adsorption; collective methods such as adsorption experiments and electrokinetic measurements [9] can lead to prejudiced interpretations if not carried out in combination with molecular spectroscopies.

The determination of anionic detergents through ion-pair formation with ternary metal complexes in solution [6] finds its close analogy at the interface of hydrous surfaces with the interacting surface functional groups and hence should be considered in phase equilibria by applying extraction procedures. Lipophilic interactions, presumably with the phospholipid layer, appear to be responsible for the strong uptake of LAS by cell material (Klebsiella pneumoniae) which is not affected by the strong complex formation of $\mathrm{Cu}^{2+}$ at protein sites as determined by EPR $\left(g_{4}=2.272, \quad A_{\|}=171 \cdot 10^{-4} \mathrm{~cm}^{-1}\right.$, $\log K$ (estimated $)=14)$ and electron nuclear double resonance spectroscopy (ENDOR). (For a recent review of the molecular structure of the bacterial outer membrane see [10].)

In future studies it will become increas- ingly important to combine molecular methods (spectroscopy) together with thermodynamic parameters (isotherms, phase equilibria) to obtain a better insight into fundamental mechanisms of surfactant binding when they are exposed to interfaces in environmental systems.

We wish to thank A. Mason for supplying Klebsiella pneumoniae cells. This project was funded by the Swiss $\mathrm{Na}$ tional Science Foundation.

Received August 1, 1985

1. McEvoy, J., Giger, W.: Naturwissenschaften 72, 429 (1985)

2. Cramer, F.: Angew. Chem. 64, 437 (1952); 68, 115 (1956)

3. Westall, J.C., Leuenberger, Ch., Schwarzenbach, R.: Environ. Sci. Technol. 19, 193 (1985)

4. Teĉak, D., et al.: Progr. Colloid Polymer Sci. 69, 100 (1984)

5. Hadiya, K., et al.: J. Phys. Chem. 88, 23 (1984)

6. Crisp, R.T., Eckert, J.M., Gibson, N.A.: Anal. Chim. Acta 78, 391 (1975)

7. Sommerauer, A., Sussman, D.L., Stumm, W.: Kolloid-Z. Z. Polymere 225, 147 (1968)

8. Burlamacchi, L., et al.: J. Colloid Surf. 7, 165 (1983)

9. Arnold, G.B., Breuer, M.M.: ibid. 13, 103 (1985); Anathapadmanabhan, K.P., Somasundaran, P.: ibid. 13, 151 (1985)

10. Nikaido, H., Vaara, M.: Microbiol. Rev. Mar. 1985, 1

11. Motschi, H.: Naturwissenschaften 70 , 519 (1983) 